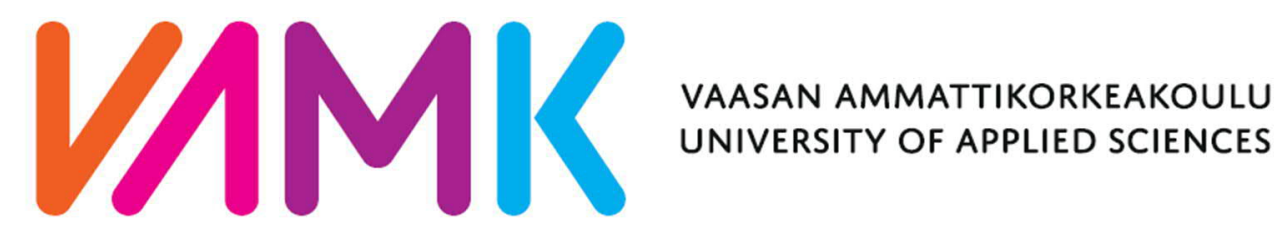

THIS IS AN ELECTRONIC REPRINT OF THE ORIGINAL ARTICLE

Please cite the original article:

Häggman-Laitila, A., Mattila, L.-R. \& Melender, H.-L. 2017. A systematic review of the outcomes of educational interventions relevant to nurses with simultaneous strategies for guideline implementation. Journal of Clinical Nursing 26 (3-4), 320-340.

https://doi.org/10.1111/jocn.13405

Version: Final draft

Copyright: @ 2017 John Wiley \& Sons Ltd 
Arja Häggman-Laitila, Lea-Riitta Mattila \& Hanna-Leena Melender

\title{
A SYSTEMATIC REVIEW OF THE OUTCOMES OF EDUCATIONAL INTERVENTIONS TO NURSES WITH SIMULTANEOUS STRATEGIES FOR GUIDELINE IMPLEMENTATION
}

\begin{abstract}
Aims. To systematically review the literature on the outcomes of educational interventions relevant to nurses with regard to guideline implementation.

Background. Previous reviews on interventions to implement guidelines have focused on particular clinical problems, but only one included nursing studies.

Design. A systematic review based on the procedure of the Centre for Reviews and Dissemination.

Methods. We searched for papers published from 1 January 2008 to 26 February 2015 using the Cochrane, CINAHL and PubMed MEDLINE databases and paper references were searched manually. Quality appraisal was conducted with tools developed by Thomas et al. and National Heart, Lung, and Blood Institute. Data were analysed with qualitative content analysis and narrative synthesis.
\end{abstract}

Results. The data included 13 studies based on a quasi-experimental study design of 13 different educational interventions, described according to their development and realisation, learning content and teaching and learning methods. Seven interventions were supported by simultaneous strategies, 12 studies reported statistically significant outcomes for the interventions on at least one measurement area and six studies reported improvements in the quality of patient care. Interventions with multidimensional content, teaching and learning methods produced several good outcomes.

Conclusion. Guidelines were implemented in a heterogeneous way and the interventions were delivered once and mainly on a local basis. In the future, we need to test these interventions in different nursing contexts, measure the outcomes on patient care and carry out randomised controlled trials on their effectiveness. It is important to standardise interventions, as this will allow them to be replicated and compared.

Relevance to clinical practice. Educational interventions to implement guidelines could be beneficial in enhancing nurses' evidence-based decision-making and care practice. The combination of teaching and learning methods proved useful and educational interventions should be supported with simultaneous strategies. There remains a lack of strong evidence on the subject. 
Keywords: evidence-based nursing, guideline implementation, educational interventions, systematic review

\section{What does this paper contribute to the wider global clinical community?}

- There is a general lack of research knowledge and evidence-based strategies on the best ways to promote the successful implementation of guidelines relevant to nurses.

- This is the first systematic review to address this issue and it shows that educational interventions that focused on implementing guidelines were effective and beneficial in enhancing nurses' evidence-based decision-making and care practices.

- Our review also showed combining teaching and learning methods was useful and that guideline implementation strategies should also employ other well-known factors that promote the implementation of evidence-based nursing. 


\section{INTRODUCTION}

The clinical practice guidelines issues by the Institute of Medicine (2011) include recommendations to optimise patient care that are based on a systematic review of the evidence and an assessment of the benefits and disadvantages of alternative care options. They form an essential basis for evidencebased decision-making for effective and safe patient care. Dale et al (2015) identified 22 factors that were assumed to inhibit or enable the implementation of guidelines in patient care. These data were gathered before the beginning of the implementation process and only a quarter of the inhibitors that they identified proved to be barriers for implementation. These were categorised into four groups: the need for new policies, a limited workforce, a lack of equipment and a lack of education and the availability of trained staff. Factors that enabled implementation included ongoing support by clinical champions, having experts in the unit who were engaged in the process, supportive leadership and easy adaption of the protocols and policies. Implementing the guidelines was a multi-phase process that required monitoring and immediate feedback for staff on positive patient outcomes (MatthewMaich et al 2012, Dale et al 2015). Implementation should be based on the organisation's readiness for change, transformational leadership (O’Byrne \& Smith 2011, Walker et al 2011, Dale et al 2015) and partnership programmes between hospitals and universities (Weeks et al 2011, Higuchi et al 2012, Matthew-Maich et al 2012). For example, nurses working in Magnet accredited hospitals have reported more advantages that nurses in non-Magnet institutions, namely fewer barriers to evidencebased nursing (EBN), higher levels of consistent EBN implementation, availability of EBN experts, an organisational culture supporting EBN, education offered routinely and recognition of EBN efforts (Melnyk et al 2012, Wilson et al 2015).

Matthew-Maich et al (2012) found several effective strategies that had been used by frontline leaders to support the uptake of guidelines. These included providing interactive education through numerous activities, rendering accountability, role modelling, collaborating with internal and external partners and facilitating and mentoring. Frontline leaders brought current research to the nurses and got them interested in using the guidelines. They inspired nurses to critically reflect on their beliefs, attitudes, feelings and previous practices. They also helped nurses to use new evidencebased practices with bedside mentoring, they followed the uptake and provided nurses with feedback on the improvements in patient care. Leaders at all organisational levels needed to be highly involved and have visible roles in supporting the implementation of guidelines and communicating the 
outcomes of new evidence-based practices. This in turn had a positive impact on the organisational culture. (Higuchi et al 2012, Hauck et al 2013.) Frontline leaders had to tailor their strategies to different groups of nurses whose attitudes towards new practices varied, including those who were eager to adopt them, those who preferred to sit on the fence and the traditional old guard who were resistant to change (Matthew-Maich et al 2012).

Previous reviews on educational interventions for implementing guidelines have focused on particular clinical problems, such as catheter-associated urinary tract infections (Willson et al 2009) and arthritis (Lineker \& Husted 2010). The review by Lineker and Husted included physicians and general practitioners, while the review by Willson et al included physicians, nurses and other healthcare professionals. These reviews revealed that there was very little literature on the implementation of guidelines. In some studies, statistically significant or clinically relevant changes were achieved by healthcare professionals adopting evidence-based practice. Studies have provided limited evidence on the EBN benefits of staff education and in particular of peer-facilitated interprofessional workshops with monitoring of care outcomes and regular feedback for staff. A systematic review by Thompson et al (2007) concluded that education was the most frequent way to implement EBN, but it was not effective on its own. For example, increased use of research was observed when education was combined with training a local opinion leader. On the basis of these conclusions (Thompson et al 2007, Willson et al 2009, Lineker \& Husted 2010) our review focused on educational interventions and simultaneous strategies that aimed to enhance the implementation of guidelines and were targeted at just nurses or nurses working in multi-professional teams. There were no restrictions on the clinical content of the guidelines. Research knowledge on the interventions and strategies for promoting the implementation of guidelines in nursing is fragmented and there is a lack of an overall evidence-based picture to guide effective guideline implementation in nursing.

\section{AIM AND RESEARCH QUESTIONS}

The aim was to systematically review the literature on the outcomes of educational interventions relevant to nurses with regard to guideline implementation. The research questions were:

1. What kind of educational interventions have been used to implement guidelines in nursing?

2. What kinds of strategies have been used in conjunction with educational interventions to support the implementation of guidelines?

3. What outcomes have been achieved by using these educational interventions and simultaneous guideline implementation strategies? 


\section{METHODS}

\section{Design}

A systematic review was conducted based on the procedure devised by the Centre for Reviews and Dissemination (2009).

\section{Search methods}

Search terms

A systematic literature search was carried out using the Cochrane, CINAHL and PubMed MEDLINE databases. This covered the period from 1 January 2008 to 26 February 2015 in order to provide upto-date data. Various search terms were purposefully selected to cover different developmental initiatives that focused on educational interventions for EBN and guideline implementation in nursing units. The terms were modified as necessary for each database (Table 1) and manual searches of the references from the selected studies were also conducted.

\section{Inclusion criteria}

We included studies where the participants were nurses or where nurses and other healthcare professionals. The studies described an educational intervention for guideline implementation, with possible simultaneous strategies, and included an evaluation of these and a report of the outcomes. Other inclusion criteria were that the abstract and full text had to be available and that the empirical research was published in English. No methodological limitations were applied.

\section{Search outcome and exclusion criteria}

Details of the study identification and selection process are shown in a PRISMA flow chart (Moher et al 2009) (Figure 1). The database searches yielded 1,437 relevant titles and, after duplicates were removed, we had 1,057 titles. After reading the titles and abstracts, 969 studies were rejected by the two authors. A total of 88 full texts were retrieved and read by the two authors and 27 of the studies met the inclusion criteria and were included in the reviews. Manual searches produced five additional studies. The final data revealed three core categories of interventions for the implementation of EBN: journal clubs, educational interventions for learning the basics and processes of EBN and educational 
interventions with simultaneous strategies for the implementation of guidelines. We decided to analyse data from these core categories separately and to report on them in three systematic reviews,

Papers were excluded if the study participants were researchers, nursing leaders or doctors. Other reasons for excluding articles were that they did not describe the intervention and contained an intervention not based on a guideline. Papers were also excluded if they described educational interventions for nurses without any connection to guideline implementation, such as critical appraisal, cognitive and research skills, problem solving or simulation. Papers were also excluded if they were descriptions of developmental projects without an evaluation by empirical studies or the description of the evaluation design was insufficient. Systematic reviews and papers on contemporary issues, such as the distribution of research knowledge, partnerships between a library and nurses and other general type of papers were excluded (Figure 1).

\section{Quality appraisal}

13 out of 14 studies (Figure 1) were subjected to quality appraisal. One study was left out at the beginning of the quality appraisal process because of lack of clarity in study participants and defects in the description of methods. Only one study was a quasi-experimental study with a comparison group while all the others were uncontrolled studies using a before- and after design. These were included in the review because of a lack of controlled studies on the subject.

The quality of the quasi-experimental study with a comparison group was evaluated in accordance with the quality assessment tool of Thomas et al (2004) using the format and dictionary published on the website of the Effective Public Health Practice Project (www.ephpp.ca). The tool includes 21 items separated into eight components: selection bias, study design, confounders, blinding, data collection methods, withdrawals and dropouts, intervention integrity and analysis. The overall methodological strength of the studies was rated strong, moderate or weak. The tool is suitable for the evaluation of non-randomized intervention studies in any public health subject area. The quality of the uncontrolled studies using a before- and after design was appraised with a tool published on the website of the National Heart, Lung, and Blood Institution (www.nhlbi.nih.gov). The tool included 12 criteria. The quality of the studies was rated good, fair or poor (Table 2).

The authors separately evaluated the studies and subsequently compared their assessments to reach a common understanding of the contents of the quality assessment criteria. The evaluations were discussed to judge the quality of the studies. The quasi-experimental study with a comparison group was evaluated by three authors and the remaining 12 studies by two authors. The overall methodological strength was moderate in the controlled quasi-experimental study (Table S1b) and good in 4 and fair in 8 of the uncontrolled studies (Table 2 and Table S1a). 


\section{Data abstraction and synthesis}

Data extraction was conducted using a descriptive matrix (Centre for Reviews and Dissemination 2009). Data were extracted from each study and placed in the matrix, namely the educational interventions and possible simultaneous strategies, participants, the evaluation design and the methods and outcomes. The information in the matrix was analysed by qualitative content analysis and narrative synthesis due to the heterogeneous nature of the guidelines, educational interventions and their evaluation methods (Centre for Reviews and Dissemination 2009, Grant \& Booth 2009). Information from the matrix was reduced and expressions with similar contexts were grouped into various subcategories based on their similarities and differences. The abstraction process was continued until the subcategories excluded each other and the subcategories were combined with similar contents to form upper categories. The categories were named based on their contents. After categorising the data, the authors studied the original material again in order to specify the contents and research evidence of the categories and the narrative synthesis. The analyses produced three main categories describing the educational interventions for guideline implementation, with 16 subcategories, plus five subcategories describing the simultaneous strategies and five subcategories describing outcomes. All these categories are presented in the text and Table 4, which includes the synthesis of the two main categories of educational interventions, with their respective subcategories, and the 10 subcategories of simultaneous strategies and outcomes.

\section{RESULTS}

\section{Description of the studies}

Table 3 shows the 13 studies that were chosen for the final analysis: 10 conducted in the USA and one each in Singapore, Iran and Australia. Three of the nine studies that focused on national guidelines were carried out in paediatric inpatient units and covered healthy eating habits (Gance-Cleveland et al 2009), venipuncture practices (Anson et al 2010) and central line care (McCaskey 2013). The other six national guideline studies focused on: asthma prevention and patient education (Policicchio et al 2011), pain assessment and management (Ang \& Chow 2010), diabetes foot ulcer assessment (Varaei et al 2013), venous thromboembolism prevention (Duff et al 2013), insulin infusion and glycaemic control in cardiac surgery (Hargraves 2014) and cervical cancer screening in adolescents (Choma \& 
McKeever 2015). The remaining four studies were based on guidelines developed locally by the researchers and colleagues for: pain assessment and management (Salinas \& Abdolrasulnia 2011) breastfeeding (Davies et al 2012), neonatal abstinence syndrome (Lucas \& Knobel 2012) and using hyaluronidase to treat intravenous extravasations (Hanrahan 2013).

\section{Development and realisation of the educational interventions}

The main category of development and realisation included subcategories such as: theoretical background, developers, duration, learning environment and intervention participants. Eight papers included information on the theoretical background of the interventions: Rogers' theory of Diffusion of Innovation (McCaskey 2013) and the Iowa model (Varaei et al 2013, Hargraves 2014), theories related to organisational empowerment (Davies et al 2012) and social marketing and persuasive communication (Duff et al 2013), social cognitive theory of self-regulation (Policicchio et al 2011) and Aizer's Theory of Planned Behaviour (Anson et al 2010). Ang and Chow (2010) used the Joanna Briggs Institute Practical Application of Clinical Evidence System (PACES) and Getting Research into Practice (GRIP) programmes. Nine papers reported interventions that had been developed for the present study: three by the researchers, one by the researchers with input from practical experts in infection control, four by multi-professional teams and one by a work group that had formulated the applied guideline. Two interventions had been developed by university staff, while one intervention had been modified by a university's centre for managing chronic disease and a national respiratory training centre based on a highly successful intervention for physicians. (see Table 3.) Varaei et al (2013) did not identify the developers of their educational intervention.

The duration of the face-to-face educational interventions in the learning environments comprised of one meeting that varied from two to five hours or consisted of one or 11 workshops or one educational outreach visit. In web-based learning environments, the duration varied from one short web-based tutorial session or a four-day workshop to five weeks (see Table 3). The durations were not described in three studies (Lucas \& Kobel 2012, Hanrahan 2013, Hargraves 2014). The participants of most of the interventions were nurses, but in one intervention (Hanrahan 2013) they also included physicians, nurse practitioners and medical residents.

\section{Learning contents of the educational interventions}

The learning contents could be divided into five subcategories: 1) the basics of searching for evidence, 2) the presentation of the guideline and the tools based on it, 3) an overview of the need to change practices according to the guideline, 4) delivering the information in the guideline to patients and families and 5) providing education and counselling to patients and families according to the 
guideline (Table 4). The presentation of the contents varied from a short mention to detailed descriptions in the original papers.

\section{Teaching and learning methods employed by the educational interventions}

The main category of teaching and learning methods consisted of six subcategories: face-to-face lectures, web-based sessions, small group work, audiovisual methods, case examples and role-play activities and demonstrations and practical exercises (Table 4). Lectures and small group work were the most popular teaching methods, with more than two teaching or learning methods being used in three of the interventions. Hanrahan (2013) did not report on the teaching and learning methods of the intervention they studied.

\section{Simultaneous strategies for implementation}

The strategies that were used simultaneously with the educational interventions to promote guideline implementation were: revisions of local procedures and protocols, facilitation and audit with feedback, support for decision-making and multi-professional collaboration (Table 4). For example, in Ang et al's (2010) study, a pain management policy was replaced by a flow chart and added to patients' medical records, with a brief introduction about its use to emphasise the importance of adopting the new practice. Two papers reported the use of facilitators and clinical rounding in the units during the educational interventions, with the focus on giving feedback about performance (Duff et al 2013, Hargraves 2014). In the study by Varaei et al (2013), a researcher assessed the nurses' performance after an intervention for three months. In McCaskey's (2013) study, audits were conducted each month for six consecutive months following the educational intervention. The results of the audits were discussed in the units during monthly staff meetings. Four simultaneous strategies for supporting clinical decision-making were used in Hanrahan's study (2013) and these included a clinical algorithm, a table of specific agents with evidence-based treatments and quick reference cards.

\section{Outcomes of the educational interventions and strategies}

Five subcategories described the outcomes of the interventions for nurses: positive changes in their attitudes, improvements in their knowledge base, enhanced confidence in using the guidelines and changing practices, self-reported improvements in their evidence-based decision-making and care practices and improvements in the quality of their care (Table 4). For example, positive changes in the nurses' attitudes included perceptions of the helpfulness of the guidelines (Policicchio et al 2011) and increased attendance at EBN educational sessions (Ang et al 2010). Enhanced confidence in 
using the guidelines and changing practices were reported. In Salina and Abdolrasulnia's (2011) study, this was described as nurses feeling "extremely confident" in their ability to provide optimal pain management for patients. After the interventions, nurses were more likely to base their decisions and care practices on evidence-based guidelines in pain assessment and management (Ang \& Crow 2010, Salinas \& Abdolrasulnia 2011), breastfeeding counselling (Davies et al 2012), venipuncture (Anson et al 2010) and central line care (McCaskey 2013) practices. There were also improvements in the quality of care (Table 4). For example, the percentage of infants who were exclusively breastfed exceeded the target in one study and there were improvements in the assessment and documentation of pain, the ability to grade intravenous infiltrates and phlebitis and the ability to master safe intravenous techniques in other studies. Nurses also reported a greater willingness to allow parents to be present during their children's venipuncture. Hanrahan (2013) reported increased incident reporting and initiation of treatment. The average time spent on treatment administration was statistically reduced and clinically significant and this effect was also visible after one year. In Hargraves's (2014) study, the incidence of hypoglycaemia was significantly reduced.

Davies et al (2012) noticed that the positive change in attitudes, knowledge and practice was sustained for three months and, in addition to the targeted goals of the intervention, changes also occurred in hospital policies and procedures. In Varaei et al's (2013) study, improvements in assessing the risk of leg ulcers were statistically significant at the end of the three-month follow-up period. Ang and Crow (2010) also reported that practice changes lasted for three months. Seven studies (Ang \& Crow 2010, Anson et al 2010, Salinas \& Abdolrasulnia 2011, Davies et al 2012, Hanharan 2013, McCaskey 2013, Varaei et al 2013) showed statistically significant outcomes on the evidence-based decision-making and care practices reported by nurses as a result of the guidelines. Six of the studies also reported improvements in the quality of care (Table 4). In one study, positive outcomes were achieved in four of the five measurement areas (Davies et al 2012). A common feature of the interventions that produced these good outcomes was that their contents were multidimensional. However, opposite results were also obtained. Duff et al (2013) concluded that educational outreach visits should not be used because they were resource-intensive and had no measurable impact on venous thromboembolism prevention in clinical practice.

\section{DISCUSSION}

\section{Validity and limitations}

To ensure that the search process was both systematic and extensive, it was carried out with an information specialist from a library and by utilising database directories. Search terms were chosen 
to produce a wide range of terms focused on evidence-based nursing, taking into account the word indexes and special features of the databases. These were reported accurately to ensure repeatability.

Two researchers worked independently to select the papers, but the selection process and ambiguous cases were discussed together, which added to the reliability of the data. The papers were initially chosen based on their titles and, therefore, it was possible that some studies may have been left out. On the other hand, the reference sections of the articles chosen for the review did not indicate any need to repeat the search process. It was unlikely that there were language or publication biases in the review as researchers didn't find any publications that may have been eligible for inclusion that were published in any language other than English when they screened the titles. The review was based on three databases and comprised articles from several journals and different cultures, including non English-speaking countries.

Relevant information about the original studies was meticulously documented in a matrix and careful use of this information in the analysis increased the reliability of the review. The main categories and subcategories contained many observations extracted from the data. Repeatability was achieved in the analysis and it may be assumed that constructing essential conceptual categories was successful, even though the scope of data was limited (Centre for Reviews and Dissemination 2009). The analysed papers have been listed and readers may verify the reported classifications based on these.

However, several limitations should be considered with regard to the review and the studies included in it. Grey literature was not searched for and this may have increased the likelihood of bias in the acquisition of material for the review. The search only included three databases, but these databases are regarded as the most comprehensive ones available in healthcare. The search terms were selected to reach the variety of interventions for guideline implementation (Table 1). In spite of this, it was possible that papers focusing on the description of something other than educational interventions, but with an educational component, may have been overlooked. Moreover, the interventions used to deliver the implementation of guidelines and the measurements used to evaluate these varied. This poor integrity, and the mixed quality of the papers, restricted the synthesis of the results. All the studies, with the exception of one, were conducted by uncontrolled quasiexperimental study designs with a before and after test. Only one used a comparison group and this could be regarded as a weakness of the study designs and the evaluations of the interventions. The uncontrolled, before and after, design is known to be vulnerable to the influence of unmeasured confounding factors and sudden organisational changes, which may falsify the outcomes of the interventions. Also, the results may be overestimated. (Grimshaw et al 2000.) Another limitation of our review concerned the implementation of the guidelines, as the studies used multiple methods and 
the descriptions of these varied when it came to the details provided. We were not able to provide exact information on how these methods were used and which of them were the most effective. The outcomes were overall estimations of the effectiveness of the educational interventions and simultaneous strategies.

The methodological strength of the intervention studies in the review was good in four and moderate in nine studies (Table S1a, b), and this is indeed one of the limitations concerning the original studies. Only five studies (Ang \& Chow 2010, Anson et al 2010, Davies et al 2012, McCaskey 2013, Varaei et al 2013) had follow-up periods of three months or more. Evaluations of the interventions were based mainly on the participants' self-assessment and, in these cases, the respondents may have chosen to answer in a more socially acceptable way than those who did not reply. Instruments were mainly developed for the purposes of the studies reviewed and the instruments had only been developed and tested in two of the earlier studies (Gance-Cleveland et al 2009, Duff et al 2013). The studies mainly took place in the USA, which must be taken into account when applying the results to different healthcare settings.

\section{Consideration of the results}

This was the first systematic review on the general implementation of guidelines relevant to nurses. We only found one previous review that covered nursing studies, but this was limited to guidelines on a particular clinical problem, namely reducing the risk of catheter-associated urinary tract infection (Willson et al 2009).

We found 13 different interventions for 13 different guidelines, of which nine were selfdeveloped. The effectiveness of the educational interventions was supported by simultaneous strategies in seven studies. The original studies provided general evaluation of the implementation and we were unable to discover data for the specific impact of these strategies. The process by which guidelines were implemented, and how the organisations' characteristics were linked to greater EBN implementation, are still poorly understood (Higuchi et al 2012, Dogherty et al 2014, Wilson et al 2015). The situation is no better in medical education. Olson et al (2011) and Phillips et al (2014) stated that research evidence on the effectiveness of continuing medical education on evidence-based practice (EBP) did not provide a strong basis for choosing intervention strategies to fit a given context. The implementation of EBN was a complicated process and it was important to support several simultaneously occurring factors related to nursing staff, leadership practices, organisational culture and the availability and applicability of evidence and the infrastructure supporting its utilisation (Gerrish et al 2011, Matthew-Maich et al 2012, Dale et al 2015). Educational interventions for guideline implementation should be an established part of promoting EBN in working communities 
and should note the previously mentioned factors. Further research is needed on the effectiveness of combining interventions and strategies for guideline implementation.

The interventions were implemented once, mainly on a local basis, and the teaching and learning methods varied. Eight of the interventions were based on theoretical background, which was different in almost all of the cases. Teachers were only mentioned in one of the studies (Lucas \& Knobel 2012) and this was also one of the most poorly described items in Phillips et al's (2014) systematic review. The most consistently reported items were information on participants' professional fields, their working environments, the number of teaching sessions, the duration of the programme and the evaluation method that was used. The review by Lineker and Husted (2010) reported that few strategies for guideline implementation were theory based and pointed out that greater use of theory may lead to the design of better interventions. Lineker and Husted (2010) and Olson et al (2011) also recommended multi-disciplinary training to implement guidelines. According to our review, multi-professional collaboration was still under-utilised in guideline implementation. Our review included studies conducted among nurses or among nurses and other healthcare professionals, but we only found four studies that reported multi-professional collaboration in guideline development or implementation.

The educational assessment categories for EBN should include: the learner's experiences of the learning process, their attitudes and knowledge of EBN, self-efficacy and skills for conducting EBN, clinical performance compatible with EBN and the benefits for patients (Tilson et al 2011). These categories were taken into account quite well in our review. Although the content of learning activities did not provide competencies for the implementation of the evidence into patient care in every case, it was still assessed and the results were good. This could be because of the simultaneous implementation strategies used to enhance the effectiveness of educational interventions. Furthermore, it is worth noting that the outcomes were evaluated with patient records and laboratory results in some of the studies. Developing the measurement of patient care and outcomes is of great importance. Positive changes in nurses' attitudes and, improvements in nurses' knowledge base, skills and self-efficacy do not, as such suffice as indicators of successful guideline implementation. The interventions on the implementation of guidelines had previously been assessed, mainly by uncontrolled quasi-experimental designs with before and after tests. However, using randomised controlled trial studies to indicate the efficacy of interventions could be set as a future goal. Strategies for implementing guidelines were an example of complex interventions (Campbell et al 2000), which comprised multiple interacting components. Process evaluation within trials was also recommended (Moore et al 2015). The realisation of interventions should also be evaluated from the viewpoint of instructors, in order to gain new perspectives for developing methods. 
Yong et al (2014) synthesised evidence from systematic reviews of studies for teaching EBP to doctors and healthcare professionals. In many cases, outcomes were narratively reported and based mostly on self-assessment. The focus was on short-term outcomes, such as attitudes, knowledge and skills of EBP and appraisal skills of studies. The current research was limited to the results of the first year of the guideline uptake (Higuchi et al 2012) and the follow-up periods of the studies included in our review were often short. However, one positive feature of our systematic review, compared to the review by Young et al (2014), was that in most of the original studies, the outcomes were described using statistical significance tests. The outcomes of the educational interventions were positive in seven studies on nurses' evidence-based decision-making and care practices based on guidelines and six of them also reported improvements in the quality of care. In one study (GanceCleveland et al 2009), outcomes were achieved in four of the five measurement areas, which showed that the educational interventions had an impact on the implementation of EBN. However, it is important to note that these outcomes were based mainly on nurses' self-evaluations. In future it is important to use multiple methods to objectively evaluate the connections between improvements in the nurses' knowledge base and their abilities to implement guidelines to improve patient care (Tilson et al 2011, Phillips et al 2014, Young et al 2014).

\section{Conclusion}

The guideline implementations were carried out in a heterogeneous way. All of the studies, except one, showed positive outcomes. Based on this review, the following conclusions can be drawn:

1. There remains a lack of strong evidence on educational interventions to implement guidelines in nursing.

2. It is very important to standardise the interventions in order to make them replicable and comparable in different nursing contexts. Interventions for guideline implementation should be described in detail.

3. Educational interventions on guideline implementation should be combined in work communities with other well-known factors and strategies that promote the implementation of EBN. Further research is needed on the implementation processes and the organisational characteristics that enhance greater implementation of the guidelines.

4. Multi-professional collaboration in guideline implementation has been inadequately studied. Educational interventions for guideline implementation should be organised, and studied, in the context of multi-disciplinary work groups. 
5. Guideline implementation should be assessed with standardised measurements and should cover all learning categories of EBN. The evaluation of the effectiveness of patient care is of great importance.

6. Attention should be paid to the stability of the outcomes with a follow-up period of more than one year. In the future, randomised controlled trials studies are needed to indicate effectiveness.

\section{Relevance to clinical practice}

Educational interventions for guideline implementation could be beneficial in enhancing nurses' evidence-based decision-making and care practices. The combination of teaching and learning methods is useful and educational interventions should be supported with simultaneous strategies.

\section{Funding Statement}

This research received no specific grant from any funding agency.

\section{Author contributions}

All authors have made substantial contributions to all of the following: 1. the conception and design of the study, acquisition of data, analysis and interpretation of data, 2. drafting the article and revising it critically and 3 . final approval of the version to be submitted.

\section{Conflict of interest}

No conflict of interest has been declared by the authors.

\section{References}

*Ang E \& Chow YL (2010) General pain assessment among patients with cancer in an acute care setting: a best practice implementation project. International Journal of Evidence Based Healthcare 8 (2), 90-6.

*Anson L, Edmundson E \& Teasley S (2010) Implications of evidence-based venipuncture practice in a pediatric health care Magnet facility. The Journal of Continuing Education in Nursing 41 (4), 179-85. 
Campbell M, Fitzpatrick R, Haines A, Kinmonth AL, Sandercock P, Spiegelhalter D \& Tyrer P (2000) Framework for design and evaluation of complex interventions to improve health. BMJ 321 (16), 694-696.

Centre for Reviews and Dissemination (2009) Systematic Reviews. CRD's Guidance for Undertaking Reviews in Health Care. University of York, York.

*Choma K \& McKeever AE (2015) Cervical Cancer Screening in Adolescents: An Evidence-Based Internet Education Program for Practice Improvement Among Advanced Practice Nurses. Worldviews on Evidence-Based Nursing 12 (1), 51-60.

Dale S, Levi C, Ward J, Grimshaw J M, Jammali-Blasi A, D’Este C, Griffiths R, Quinn C, Evans M, Cadilhac D, Cheung NW \& Middleton S (2015) Barriers and Enablers to Implementing Clinical Treatment Protocols for Fever, Hyperglycaemia, and Swallowing Dysfunction in the Quality in Acute Stroke Care (QASC) Project - A Mixed Methods Study. Worldviews on Evidence-Based Nursing 12 (1), 41-50.

*Davis SK, Stichler JF \& Poeltler DM (2012) Increasing exclusive breastfeeding rates in the well-baby population: an evidence-based change project. Nursing of Women's Health 16 (6), 460-70.

Dogherty EJ, Harrison M, Graham I \& Keeping-Burke L (2014) Examining the use of facilitation within guideline dissemination and implementation studies in nursing. International Journal of Evidence-Based Healthcare 12 (2), 105-27.

*Duff J, Walker K, Omari A, Middleton S \& McInnes E (2013) Educational outreach visits to improve nurses' use of mechanical venous thromboembolism prevention in hospitalized medical patients. Journal of Vascular Nursing 31 (4), 139-49.

Effective Public Health Practice Project (2016) Quality Assessment Tool for Quantitative Studies. Available at: http://www.ephpp.ca (Accessed 24 March 2016).

Effective Public Health Practice Project (2016) Quality Assessment Tool for Quantitative Studies Dictionary. Available at: http://www.ephpp.ca (Accessed 24 March 2016).

*Gance-Cleveland B, Sidora-Arcoleo K, Keesing H, Gottesman MM \& Brady M (2009) Changes in nurse practitioners' knowledge and behaviors following brief training on the healthy eating and activity together (HEAT) guidelines. Journal of Pediatric Healthcare 23 (4), 222-230.

Grant MJ \& Booth A (2009) A typology of reviews: an analysis of 14 review types and associated methodologies. Health Information and Libraries Journal 26, 91-108.

Grimshaw J, Campbell M, Eccles M \& Seen N (2000) Experimental and quasi-experimental designs for evaluating guideline implementation strategies. Family Practice 17 (1), 11-16. 
Johansson B, Fogelberg-Dahm M \& Wadensten B (2010) Evidence-based practice: the importance of education and leadership. Journal of Nursing Management 18, 70-77.

*Hanrahan K (2013) Hyaluronidase for treatment of intravenous extravasations: Implementation of an evidence-based guideline in a pediatric population. Journal for Specialists in Pediatric Nursing 18 (3), 253-62.

*Hargraves JD (2014) Glycemic control in cardiac surgery: implementing an evidence-based insulin infusion protocol. American Journal of Critical Care 23 (3), 250-8.

Hauck S, Winsett RP \& Kuric J (2013) Leadership facilitation strategies to establish evidencebased practice in an acute care hospital. Journal of Advanced Nursing 69 (3), 664-674.

Higuchi KS, Downey A, Davies B, Bajnok I \& Waggott M (2012) Using the NHS sustainability framework to understand the activities and resource implications of Canadian nursing guideline early adopters. Journal of Clinical Nursing 22, 17071716.

Institute of Medicine (2011) Clinical Practice Guidelines. We Can Trust. Washington, DC: The National Academic Press.

Lineker SC \& Husted JA (2010) Educational interventions for implementation of arthritis clinical practice guidelines in primary care: effects on health professional behaviour. Journal of Rheumatology 37 (8), 1562-1569.

*Lucas K \& Knobel RB (2012) Implementing practice guidelines and education to improve care of infants with neonatal abstinence syndrome. Advances in Neonatal Care 12 (1), 40-45.

Matthew-Maich N, Ploeg J, Jack S \& Dobbins M (2012) Leading on the frontlines with passion and persistence: a necessary condition for Breastfeeding Best Practice Guideline uptake. Journal of Clinical Nursing 22, 1759-1770.

*McCaskey MS (2013) Transferring Central Line Care Evidence Into Practice on Pediatric Acute Care Units. Journal of Pediatric Nursing 28 (6), e57-63.

Melnyk BM, Fineout-Overholt E, Gallagher L \& Kaplan L (2012) The State of EvidenceBased Practice in US Nurses. Critical Implications for Nurse Leaders and Educators. The Journal of Nursing Administration 42 (9), 410-417.

Moher D, Liberati A, Tetzlaff J \& Altman DG (2009) Preferred reporting items for systematic reviews and meta-anlyses: the PRISMA statement. Open Medicine 3 (3), 123-130.

Moore GF, Audrey S, Barker M, Bond L, Bonell C, Hardeman W, Moore L, O'Cathain A, Tinati T, Wight D \& Baird J (2015) Process evaluation of complex interventions: Medical Research Council 
guidance. BMJ 350: h 1258 doi: 10.1136/bmj.h1248.

National Heart, Lung, and Blood Institute (2016) Quality assessment tool for before-after (pre-post) studies with no control group. Available at: http:// www.nhlbi.nih.gov (Accessed 29 April 2016).

O'Byrne L \& Smith S (2011) Models to enhance research capacity and capability in clinical nurses: a narrative review. Journal of Clinical Nursing 20 (9-10), 1365-1371.

Olson CA, Shershneva MB \& Brownstein MH (2011) Peering inside the clock: Using success case method to determine how and why practice-based educational interventions succeed. Journal of Continuing Education in the Health Professions 31, Supplement, S50-59.

Phillips AC, Lewis LK, McEvoy MP, Galipeau J, Glasziou P, Hammick M, Moher D, Tilson JK \& Williams MT (2014) A systematic review of how studies describe educational interventions for evidence-based practice: stage 1 of the development of a reporting guide. BMC Medical Education 14, 152.

*Policicchio J, Nelson B \& Duffy S (2011) Bringing evidence-based continuing education on asthma to nurses. Clinical Nurse Specialist 25 (3), 125-132.

Rogers JL (2009) Transferring Research Into Practice. An Integrative Review. Clinical Nurse Specialist 23 (4), 192-199.

*Salinas GD \& Abdolrasulnia M (2011) Effectiveness of INROADS into pain management, a nursing educational intervention. The Journal of Continuing Education in Nursing 42 (7), 328-336.

Thomas BH, Ciliska D, Dobbins M \& Micucci S (2004) A process for systematically reviewing the literature: providing the research evidence for public health nursing interventions. Worldviews on Evidence-based Nursing 1, 176-184.

Thompson D, Estabrooks C, Scott-Findlay S, Moore K \& Wallin L (2007) Interventions aimed at increasing research use in nursing: A systematic review. Implementation Science 2 (1), 1-16.

Tilson JK, Kaplan SL, Harris JL, Hutchinson A, Ilic D, Niederman R, Potomkova J \& Zwolsman SE (2011) Sicily statement on classification and development of evidencebased practice learning assessment tools. BMC Medical Education 11, 78.

*Varaei S, Salsali M, Cheraghi MA, Tehrani MR \& Heshmat R (2013) Education and implementing evidence-based nursing practice for diabetic patients. Iran Journal of Nursing and Midwifery Research 18 (3), 251-7.

Walker R, Cooke M, Henderson A \& Creedy DK (2011) Characteristics of leadership that 
influence clinical learning: A narrative review. Nurse Education Today 31, 743-756.

Weeks SM, Moore P \& Allender M (2011) A Regional Evidence-Based Practice Fellowship. Collaborative Competitors. The Journal of Nursing Administration 41 (1), 10-14.

Willson M,Wilde M, Webb M, Thompson D, Parker D, Harwood J, Callan L \& Gray M (2009) Nursing interventions to reduce the risk of catheter-associated urinary tract infection: part 2: staff education, monitoring, and care techniques. Journal of Wound, Ostomy \& Continence Nursing 36 (2), 137-154.

Wilson M, Sleutel M, Newcomb P, Behan D, Walsh J, Wells JN \& Baldwin KM (2015) Empowering nurses with evidence-based practice environments: surveying magnet $\AA$, pathway to excellence ${ }^{\circledR}$, and non-magnet facilities in one healthcare system. Worldviews on Evidence-Based Nursing 2 (1), 12-21.

Yost J, Thompson D, Ganann R, Aloweni F, Newman K, McKibbon A, Dobbins M \& Ciliska D (2014) Knowledge translation strategies for enhancing nurses' evidence-informed decision-making: a scoping review. Worldviews on Evidence-Based Nursing 11 (3), 156-67.

Young T, Rohwer A, Volmink J \& Clarke M (2014) What Are the Effects of Teaching EvidenceBased Health Care (EBHC)? Overview of Systematic Reviews. PLOS ONE 9 (1): e86706. doi:10.1371/journal.pone.0086706.

Included in the review $(*)$ 


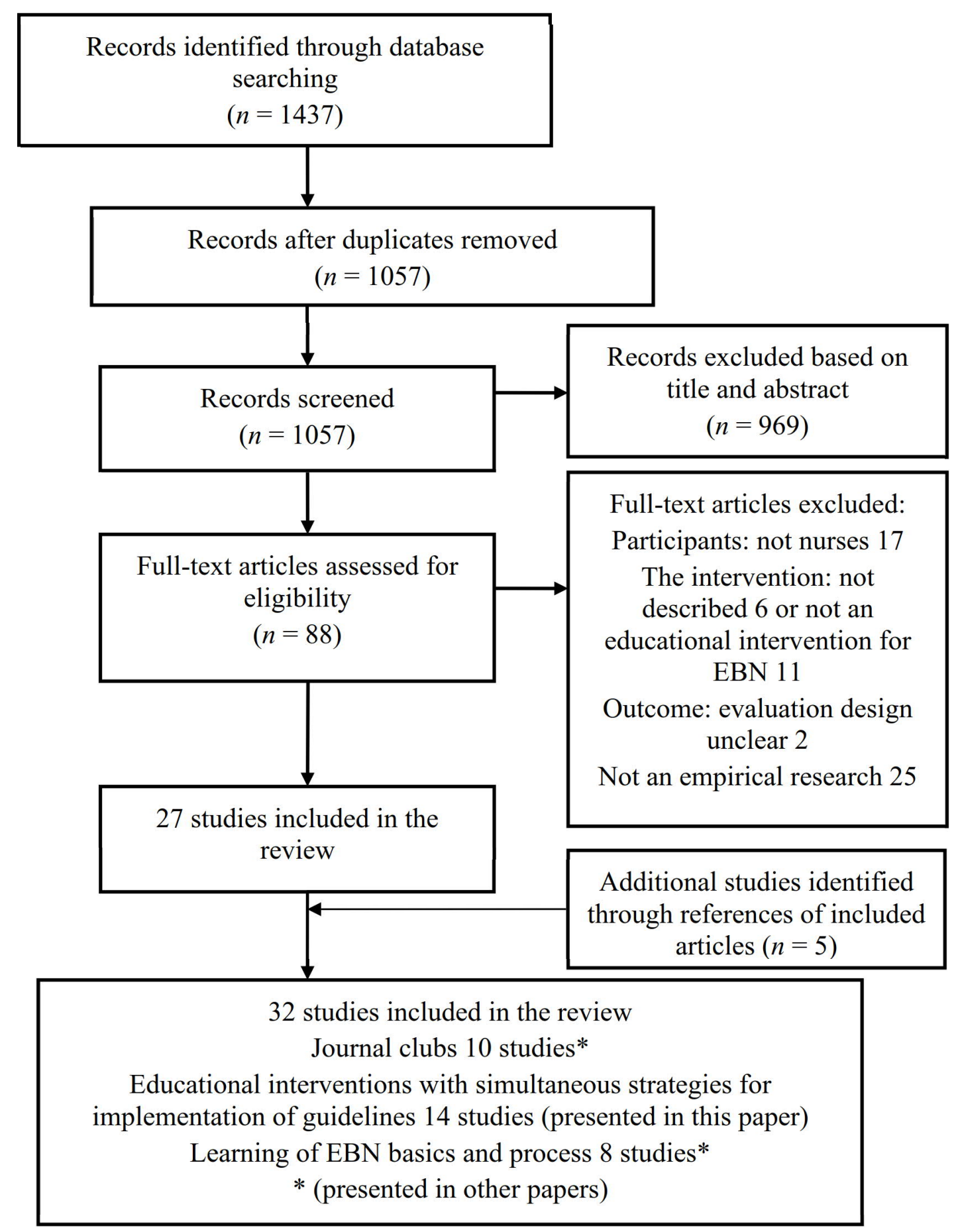

Figure 1. PRISMA flow chart. 
Table 1. Search terms from databases.

\begin{tabular}{|c|c|c|}
\hline Cinahl & PubMed & Cochrane \\
\hline $\begin{array}{l}\text { (MH "Research, Nursing") AND } \\
\text { journal clubs OR (MH "Professional } \\
\text { Practice, Research-Based") OR (MH } \\
\text { "Nursing Practice, Research-Based") } \\
\text { OR (MH "Nursing Practice, } \\
\text { Evidence-Based") OR (MH "Practice } \\
\text { Guidelines"), (MH "Quality } \\
\text { Improvement") OR (MH "Quality } \\
\text { Assessment") OR (MH "Quality } \\
\text { Management, Organizational") OR } \\
\text { (MH "Evaluation and Quality } \\
\text { Improvement Program") OR (MH } \\
\text { "Quality of Nursing Care"), (MH } \\
\text { "Collaboration"), Peer Reviewed; } \\
\text { Research Article }\end{array}$ & $\begin{array}{l}\text { "Evidence-Based Nursing" AND } \\
\text { journal clubs AND ("nursing } \\
\text { education" OR collaboration OR } \\
\text { quality OR development* OR } \\
\text { improvement*), Case Reports; } \\
\text { Journal Article; Clinical Trial; } \\
\text { Evaluation Studies; Meta-Analysis; } \\
\text { Practice Guideline; Randomized } \\
\text { Controlled Trial; Review }\end{array}$ & $\begin{array}{l}\text { '"Evidence-based nursing", } \\
\text { Cochrane Reviews, Other } \\
\text { Reviews, Trials, Methods } \\
\text { Studies, Technology } \\
\text { Assessments, Economic } \\
\text { Evaluations, Cochrane Groups }\end{array}$ \\
\hline
\end{tabular}


Table 2. Summary of the quality assessment of uncontrolled studies using a before- and after design (National Heart, Lung, and Blood Institute 2016).

\begin{tabular}{|c|c|c|c|}
\hline Quality appraisal criteria & $\begin{array}{l}\text { Yes/ } \\
\text { studies (n) }\end{array}$ & $\begin{array}{l}\text { No/ } \\
\text { studies (n) }\end{array}$ & $\begin{array}{l}\text { Other* } \\
\text { (CD, NR, NA)/ } \\
\text { studies (n) }\end{array}$ \\
\hline 1. Was the study question or objective clearly stated? & 10 & 2 & \\
\hline $\begin{array}{l}\text { 2. Were eligibility/selection criteria for the study population prespecified and } \\
\text { clearly described? }\end{array}$ & 12 & & \\
\hline $\begin{array}{l}\text { 3. Were the participants in the study representative of those who would be } \\
\text { eligible for the test/service/ intervention in the general or clinical population of } \\
\text { interest? }\end{array}$ & 12 & & \\
\hline $\begin{array}{l}\text { 4. Were all eligible participants that met the prespecified entry criteria } \\
\text { enrolled? }\end{array}$ & 3 & 8 & 1 \\
\hline 5. Was the sample size sufficiently large to provide confidence in the findings? & 5 & 7 & \\
\hline $\begin{array}{l}\text { 6. Was the test/service/intervention clearly described and delivered consistently } \\
\text { across the study population? }\end{array}$ & 12 & & \\
\hline $\begin{array}{l}\text { 7. Were the outcome measures prespecified, clearly defined, valid, reliable, and } \\
\text { assessed consistently across all study participants? }\end{array}$ & 10 & 2 & \\
\hline $\begin{array}{l}\text { 8. Were the people assessing the outcomes blinded to the participants' } \\
\text { exposures/interventions? }\end{array}$ & & 11 & 1 \\
\hline $\begin{array}{l}\text { 9. Was the loss to follow-up after baseline } 20 \% \text { or less? Were those lost to } \\
\text { follow-up accounted for in the analysis? }\end{array}$ & 8 & 3 & 1 \\
\hline $\begin{array}{l}\text { 10. Did the statistical methods examine changes in outcome measures from } \\
\text { before to after the intervention? Were statistical tests done that provided } p \\
\text { values for the pre-to-post changes? }\end{array}$ & 12 & & \\
\hline $\begin{array}{l}\text { 11. Were outcome measures of interest taken multiple times before the } \\
\text { intervention and multiple times after the intervention (i.e., did they use an } \\
\text { interrupted time-series design)? }\end{array}$ & 6 & 6 & \\
\hline $\begin{array}{l}\text { 12. If the intervention was conducted at a group level (e.g., a whole hospital, a } \\
\text { community, etc.) did the statistical analysis take into account the use of } \\
\text { individual-level data to determine effects at the group level? }\end{array}$ & 12 & & \\
\hline Quality rating (good, fair and poor) & & & \\
\hline
\end{tabular}

$\mathrm{CD}=$ cannot determine; $\mathrm{NA}=$ not applicable; $\mathrm{NR}=$ not reported

\section{Quality appraisal/study (Table S1a):}

- Good=Yes, determined 9 times or more

- Fair= Yes, determined 6 to 8 times Poor $=$ Yes, determined less than 6 times 
Table 3. Description of the studies in the review.

\begin{tabular}{|c|c|c|c|c|}
\hline $\begin{array}{l}\text { Authors (publication } \\
\text { year), country, study } \\
\text { design }\end{array}$ & Intervention & $\begin{array}{l}\text { Setting, participants and } \\
\text { response rates }\end{array}$ & $\begin{array}{l}\text { Instruments and data collection with } \\
\text { evaluation periods and data analyses }\end{array}$ & Outcomes \\
\hline $\begin{array}{l}\text { Choma \& McKeever } \\
\text { (2015), USA } \\
\text { Pre- and posttest CEU } \\
\text { evaluation }\end{array}$ & $\begin{array}{l}\text { Web-based designed continuing educational } \\
\text { (CEU) Internet intervention developed by } \\
\text { the researchers targeted to HPV infection } \\
\text { and cervical cancer screening among } \\
\text { adolescents and implementation of ACOG } \\
\text { Cervical Cytology Screening guidelines, } \\
\text { available } 5 \text { weeks, } \\
\text { Power point presentations }\end{array}$ & $\begin{array}{l}\text { Members of New Jersey State } \\
\text { Nurses Association } \\
78 \text { advanced practice nurses } \\
\text { (APN) completed the contact } \\
\text { hour program, } 61 \%(n=48) \\
\text { participated in both the program } \\
\text { and post program survey. }\end{array}$ & $\begin{array}{l}\text { Questionnaire developed by the author for } \\
\text { assessment of knowledge levels related to } \\
\text { guidelines and to evaluate the course } \\
\text { objectives, the presenter, the experiences } \\
\text { with the program, } 3 \text { weeks after closing the } \\
\text { program } \\
\text { Descriptive statistics, SPSS version 19.0, } \\
\text { paired-sample t-test. }\end{array}$ & $\begin{array}{l}\text { APNs knowledge level increased } \\
\text { statistically significantly from the } \\
\text { pretest to posttest. Participants rated } \\
\text { the objectives, presenter and use of } \\
\text { eLearning method as good to } \\
\text { excellent. The program either } \\
\text { improved or validated the } \\
\text { participants' clinical practice. }\end{array}$ \\
\hline $\begin{array}{l}\text { Hargraves (2014), USA } \\
\text { Study design not } \\
\text { mentioned in the paper. } \\
\text { Identified by the authors } \\
\text { as a quasi-experimental } \\
\text { design with before and } \\
\text { after tests }\end{array}$ & $\begin{array}{l}\text { Revision the outdated insulin infusion } \\
\text { protocol (IIP) according to the guideline of } \\
\text { Society of Critical Care Medicine: } \\
\text { Guidelines for the Use of an Insulin Infusion } \\
\text { for the Management of Hyperglycemia in } \\
\text { Critically Ill Patients by a multi-professional } \\
\text { team and implementation of the protocol. } \\
\text { Educational intervention developed by the } \\
\text { multi-professional team with power point } \\
\text { presentation: titration of an insulin infusion, } \\
\text { blood glucose monitoring during insulin } \\
\text { therapy and instructions for insulin infusion. } \\
\text { CNS was available during clinical rounds } \\
\text { and by e-mail or phone to answer questions. }\end{array}$ & $\begin{array}{l}\text { Cardiac surgery, } \\
29 \text { critical care nurses, } \\
\text { Pretest } n=29, \text { posttest } n=27 .\end{array}$ & $\begin{array}{l}\text { Tests designed for this study to measure } \\
\text { nurses' knowledge of glycemic control. } \\
\text { Retrospective review of electronic health } \\
\text { records using a self-developed tool on } 76 \\
\text { patients. Two months before ( } \mathrm{n}=48 \\
\text { patients) and two months after the } \\
\text { intervention (n=28 patients). } \\
\text { Descriptive and inferential statistics, A 1- } \\
\text { tailed test (knowledge), 2-tailed t test to } \\
\text { compare patients' age, Chi square test to } \\
\text { compare history of diabetes. }\end{array}$ & $\begin{array}{l}\text { A significant increase in nurses' } \\
\text { knowledge after education. } \\
\text { The incidence of hypoglycemia was } \\
\text { significantly reduced after the } \\
\text { intervention. The percentage of blood } \\
\text { glucose levels less than } 180 \mathrm{mg} / \mathrm{dl} \\
\text { was } 88 \% \text { (a goal according to the } \\
\text { guideline). }\end{array}$ \\
\hline $\begin{array}{l}\text { Duff et al (2013), } \\
\text { Australia } \\
\text { A prospective, } \\
\text { uncontrolled, before-and- } \\
\text { after intervention study } \\
\text { with process evaluation } \\
\text { using pre- and post- } \\
\text { intervention clinical } \\
\text { audits and self- } \\
\text { administered surveys }\end{array}$ & $\begin{array}{l}\text { The educational outreach visits (EOV) } \\
\text { protocol was developed by a } \\
\text { multidisciplinary group of healthcare } \\
\text { professionals with expertise in mechanical } \\
\text { VTE prophylaxis, clinical education, } \\
\text { healthcare improvement science and } \\
\text { research to improve the implementation of } \\
\text { VTE risk assessment tool based on national } \\
\text { guidelines. } \\
\text { A registered nurse with expertise in VTE } \\
\text { was recruited and educated (a 2-day } \\
\text { intensive workshop with research team) to } \\
\text { the role of EOV facilitator. She conducted } \\
\text { face-to-face educational visits to a health }\end{array}$ & $\begin{array}{l}\text { Medical units of Magnet- } \\
\text { designated private hospital } \\
\text { Out of the } 85 \text { nurses who } \\
\text { participated in the intervention, } \\
76(89 \%) \text { returned the post- } \\
\text { intervention participant survey. } \\
\text { The } 192 \text { patients who met the } \\
\text { criteria were audited before ( } \mathrm{n}= \\
\text { 98) and after ( } \mathrm{n}=94) \text { the EOV } \\
\text { intervention period ( } 2 \text { months) }\end{array}$ & $\begin{array}{l}\text { Participant survey developed for this } \\
\text { study, eight questions: effectiveness of the } \\
\text { EOV on participants' knowledge and } \\
\text { clinical practice, addressing their concerns } \\
\text { about VTE prophylaxis and the } \\
\text { acceptability of the course. } \\
\text { Before tested audit tool based on national } \\
\text { VTE prevention guidelines: the proportion } \\
\text { of inpatients with a documented VTE risk } \\
\text { assessment and receiving appropriate } \\
\text { prophylaxis. The facilitator completed a } \\
\text { post- intervention survey appraising each } \\
\text { participant's perceived level of interest, } \\
\text { participation, and comprehension, how the }\end{array}$ & $\begin{array}{l}97 \% \text { nurses felt that the EOV was } \\
\text { effective or extremely effective at } \\
\text { increasing their knowledge and } \\
\text { addressing their concerns about VTE } \\
\text { prophylaxis. The EOV facilitator } \\
\text { reported that } 95 \% \text { of the participants } \\
\text { had a high or very high level of } \\
\text { interest and participation, and } 86 \% \\
\text { of them had a high or very high level } \\
\text { of comprehension. } \\
\text { No measurable improvement in the } \\
\text { proportion of patients with a } \\
\text { documented VTE risk assessment } \\
\text { after the intervention period, and no }\end{array}$ \\
\hline
\end{tabular}




\begin{tabular}{|c|c|c|c|c|}
\hline & $\begin{array}{l}\text { professional in their own clinical setting ( } 2- \\
\text { month intervention period) based on four } \\
\text { verbal key messages: consequences of VTE, } \\
\text { importance of the assessment, appropriate } \\
\text { prophylaxis and monitoring. }\end{array}$ & & $\begin{array}{l}\text { EOV was implemented and the degree to } \\
\text { which the intervention was implemented } \\
\text { as intended (utility) } \\
\text { SPSS version } 18.0 \text {, descriptive statistics, } \\
\text { the chi-square test and Mann-Whitney U- } \\
\text { test, } 95 \% \text { confidence intervals }\end{array}$ & $\begin{array}{l}\text { improvement in the proportion of } \\
\text { patients who received appropriate } \\
\text { mechanical VTE prophylaxis. } \\
\text { Removing patients who were at low } \\
\text { risk for VTE from the analysis made } \\
\text { no difference to this result. }\end{array}$ \\
\hline $\begin{array}{l}\text { Hanrahan (2013), USA } \\
\text { Study design not } \\
\text { mentioned in the paper. } \\
\text { Identified by the authors } \\
\text { as a quasi-experimental } \\
\text { design with before and } \\
\text { after tests }\end{array}$ & $\begin{array}{l}\text { The guideline Hyaluronidase for Treatment } \\
\text { of IV Extravasations was developed } \\
\text { systematically using } 28 \text { research articles, } 34 \\
\text { guidelines, reviews and other publications } \\
\text { by a collaborative interdisciplinary process } \\
\text { that involved academicians and clinicians. } \\
\text { A multiprofessional team used the guideline } \\
\text { for updating of the pediatric standard of } \\
\text { practice (SOP) for IV extravasations. The } \\
\text { SOP included a clinical algorithm, a table of } \\
\text { specific agents with evidence-based } \\
\text { treatments and quick reference cards. } \\
\text { Standardized documentation, treatment and } \\
\text { order sets were supported by automated } \\
\text { computerized documentation and electronic } \\
\text { healthcare record (EHR). Multidisciplinary } \\
\text { education for participants. }\end{array}$ & $\begin{array}{l}\text { Academic children's hospital } \\
\text { (general unit and NICU) } 600 \\
\text { RNs and } 600 \text { LIPs (licensed } \\
\text { independent providers). A total } \\
\text { of } 175 \text { staff participated at } \\
\text { baseline (return rate } 15 \% \text { ), } 100 \\
\text { at } 6 \text { months post- } \\
\text { implementation (response rate } 8 \\
\% \text { ). Participants were mostly } \\
\text { staff nurses } 70 \% \text { at baseline, } 71 \\
\% \text { post-imp. Also nurse } \\
\text { practitioners, residents and } \\
\text { physicians. }\end{array}$ & $\begin{array}{l}\text { An online knowledge survey at baseline } \\
\text { and at 6-month post-implementation ( } 4 \\
\text { demographic questions and } 10 \text { questions } \\
\text { about hyaluronidase from the guideline } \\
\text { knowledge test). } \\
\text { Incident reports from the electronic } \\
\text { medication administration (EMAR): } \\
\text { analysis of extravasation incidents, } \\
\text { treatment, outcomes by reviewing Patient } \\
\text { Safety Net, to determine if treatment } \\
\text { resulted in less harm, subjects were } \\
\text { collapsed into two groups: those receiving } \\
\text { hyaluronidase and those who did not and a } \\
\text { retrospective review to capture the use of } \\
\text { hyaluronidase } 6 \text { month pre- and } 6 \text { months } \\
\text { post-implementation and } 12 \text { months } \\
\text { maintenance periods. } \\
\text { Time from discovery to treatment as } \\
\text { documented in nursing notes in minute. } \\
\text { Descriptive statistics were analyzed using } \\
\text { Survey and Excel software. }\end{array}$ & $\begin{array}{l}\text { Overall shift toward increased user } \\
\text { knowledge, increased incident } \\
\text { reporting, statistically significant } \\
\text { decrease in the mean of time to } \\
\text { treatment administration and } \\
\text { increased preparedness to manage an } \\
\text { extravasation } 6 \text { months after } \\
\text { implementation the guideline. There } \\
\text { was a trend toward lower scores and } \\
\text { a reduction in the percentage of } \\
\text { events resulting in harm to patient } \\
\text { during the maintenance period. } \\
\text { There was an increase in the number } \\
\text { of hyaluronidase treatments from the } \\
\text { pre-implementation compared with } \\
\text { post - implementation period. The } \\
\text { rate of hyaluronidase treatment in the } \\
\text { maintenance period was sustained } \\
\text { and also increased compared with } \\
\text { post-implementation period. The } \\
\text { time to treatment administration in } \\
\text { the maintenance period was not } \\
\text { statistically different from post- } \\
\text { implementation. }\end{array}$ \\
\hline $\begin{array}{l}\text { McCaskey (2013), USA } \\
\text { A quasi-experimental } \\
\text { unmatched pre and post- } \\
\text { intervention design. }\end{array}$ & $\begin{array}{l}\text { A multi-pronged educational intervention } \\
\text { promoting CLABSI (confirmed bloodstream } \\
\text { infection) prevention including electronic } \\
\text { educational sessions (available } 4 \text { weeks), } \\
\text { hands-on demonstration, small group } \\
\text { discussion, audit and feedback on the } \\
\text { implementation of a central line } \\
\text { maintenance care bundle. } \\
\text { The electronic learning module was } \\
\text { developed by the researchers with the input } \\
\text { from practical experts to include the content }\end{array}$ & $\begin{array}{l}\text { Inpatient surgical care units of } \\
\text { children' hospital } \\
187 \text { full-time nurses from were } \\
\text { invited to participate in the pre } \\
\text { and post intervention self- } \\
\text { reporting surveys. } 56 \% \text { (n } \\
=105 \text { ) completed the pre- } \\
\text { intervention survey and } 51.8 \% \\
\text { completed the post- intervention } \\
\text { survey }\end{array}$ & $\begin{array}{l}\text { A } 15 \text {-question survey designed for this } \\
\text { study, seven components of the } \\
\text { maintenance care bundle. The audit and } \\
\text { feedback on the implementation of a care } \\
\text { bundle, the second and fourth Thursday of } \\
\text { each month for six months following the } \\
\text { intervention. } \\
\text { The incidence of CLABSI was recorded } \\
\text { during the same 4-month period. Incidence } \\
\text { was reported in raw numbers in lieu of the } \\
\text { typical infection per } 1000 \text { line-day rate. }\end{array}$ & $\begin{array}{l}\text { The mean total compliance score of } \\
\text { the post-intervention respondents } \\
\text { was significantly higher compared } \\
\text { with the pre-intervention } \\
\text { respondents. } \\
\text { Audit results of the dressing-care } \\
\text { integrity and last change day did } \\
\text { improve over time. This was possibly } \\
\text { related to a Hawthorne effect. }\end{array}$ \\
\hline
\end{tabular}




\begin{tabular}{|c|c|c|c|c|}
\hline & $\begin{array}{l}\text { of the bundle: daily discussions of central } \\
\text { line necessity, daily assessment of the } \\
\text { central line dressing, standardized central } \\
\text { line entry procedure, dressing, cap and } \\
\text { tubing change procedure. }\end{array}$ & & $\begin{array}{l}\text { SPSS version 18.0, descriptive statistics, } \\
\text { independent samples t-test, two-way } \\
\text { ANOVA and Chi-square for } \\
\text { independence. }\end{array}$ & $\begin{array}{l}\text { Two few infections occurred to } \\
\text { detect a statistically significant } \\
\text { decrease in CLABSI. }\end{array}$ \\
\hline $\begin{array}{l}\text { Varaei } \text { et al (2013), Iran } \\
\text { Quasi-experimental study } \\
\text { using a before- and -after } \\
\text { design. }\end{array}$ & $\begin{array}{l}\text { A 4-days workshop for three groups }(6-7 \\
\text { members in each): developing a clinical } \\
\text { question using the PICO format, searching } \\
\text { for evidence, reading and critiquing nursing } \\
\text { research, discussing articles, synthesizing } \\
\text { evidence, and developing a summary of } \\
\text { findings. } \\
\text { The researcher was present as a helper in the } \\
\text { ward. }\end{array}$ & $\begin{array}{l}\text { Endocrinology ward } \\
19 \text { baccalaureate nurses, } \\
\text { (response rate } 100 \% \text { ) }\end{array}$ & $\begin{array}{l}\text { Self-report questionnaire, designed for this } \\
\text { study: nurses' knowledge about and } \\
\text { attitude to EBN approach and EBN } \\
\text { practice. A checklist based on the national } \\
\text { and regional clinical guideline for the } \\
\text { evaluation of nurses' skills in the } \\
\text { performance and assessment of people } \\
\text { with diabetes foot ulcer, filled in by a } \\
\text { researcher. The performance assessment } \\
\text { after intervention was conducted more } \\
\text { than once for each nurse within a period of } \\
3 \text { months. } \\
\text { SPSS version } 11.5 \text {, descriptive and } \\
\text { inferential statistics. }\end{array}$ & $\begin{array}{l}\text { The mean scores for nurses' } \\
\text { knowledge about EBN, attitude to } \\
\text { EBN and EBN practice were } \\
\text { statistically significantly higher after } \\
\text { the intervention. } \\
\text { The nurses' performance in caring } \\
\text { for patients with diabetes foot ulcer, } \\
\text { based on clinical guideline, showed } \\
\text { statistically significant improvement } \\
\text { after the intervention. }\end{array}$ \\
\hline $\begin{array}{l}\text { Davis } \text { et al (2012), USA } \\
\text { Pre-/post-test } \\
\text { methodology }\end{array}$ & $\begin{array}{l}\text { Hospital leadership engaged nurses, nurse } \\
\text { assistants, managers, physicians and nurse } \\
\text { lactation consults and educators as change } \\
\text { agents and in the development of the } \\
\text { educational intervention according to the } \\
\text { requirements of the Baby-Friendly Hospital } \\
\text { Initiative. 2-hour class evidence-based } \\
\text { knowledge: breastfeeding as a health care } \\
\text { issue, the importance of exclusive } \\
\text { breastfeeding, skin-to-skin concepts, } \\
\text { common questions of mothers and } \\
\text { appropriate provider responses, support } \\
\text { strategies for parents and common } \\
\text { challenges of breastfeeding in the early } \\
\text { postpartum period. Changes in hospital } \\
\text { policies and procedures. }\end{array}$ & $\begin{array}{l}\text { Maternal Infant Services (MIS) } \\
\text { units } \\
32 \text { nurses } \\
\text { Pre, } n=32 \text {, post } 1, n=30 \text { and post } \\
2 \text { (after } 3 \text { months), } n=30\end{array}$ & $\begin{array}{l}\text { Survey developed by hospital to measure } \\
\text { nurses' knowledge, attitudes and practice } \\
\text { of breastfeeding, eight-item demographic } \\
\text { and } 12 \text { multiple choice and true/false } \\
\text { questions, } \\
\text { Measuring the differences in the scores } \\
\text { and correlations, independent t-test }\end{array}$ & $\begin{array}{l}\text { Significant differences in attitudes, } \\
\text { knowledge and practice of the MIS } \\
\text { between the pretest and the first and } \\
\text { second posttest indicating that the } \\
\text { change was sustained during the } \\
\text { period of time. } \\
\text { The percentage of infants exclusively } \\
\text { breastfeeding improved to } 70.4 \\
\text { beyond the stated goal one year after } \\
\text { the change project was completed. }\end{array}$ \\
\hline $\begin{array}{l}\text { Lucas \& Knobel (2012), } \\
\text { USA } \\
\text { A nonexperimental, } \\
\text { pretest/postest study }\end{array}$ & $\begin{array}{l}\text { The clinical guideline was developed based } \\
\text { on a review of literature to incorporates all } \\
\text { aspects of neonatal abstinence syndrome } \\
\text { (NAS) from etiology to discharge of the } \\
\text { patient }\end{array}$ & $\begin{array}{l}\text { Intensive care unit for newborn } \\
68 \text { nurses, Pre, } n=68, \text { post, }=68, \\
10 \text { nurses independently } \\
\text { observed a DVD of an infant } \\
\text { with NAS and scored the infant, } \\
\text { using the FNAST, an interrater }\end{array}$ & $\begin{array}{l}\text { NAS test (58 questions) developed for the } \\
\text { study to evaluate knowledge of NAS, care } \\
\text { of infant and use of the FNAST } \\
\text { SPSS Version 19.0, descriptive statistics, } \\
\text { paired samples test }\end{array}$ & $\begin{array}{l}\text { All of the nurses showed some } \\
\text { improvement representing increase in } \\
\text { knowledge }(2 \% \text { to } 44 \%) \text { on the } \\
\text { posttest scores. Sixty-one of the } \\
\text { participants showed a } 10 \% \text { or more } \\
\text { improvement in scores on the }\end{array}$ \\
\hline
\end{tabular}




\section{USA}

A quasi-experimental study using a pre-post design.

\section{Salinas \&}

Abdolrasulnia (2011),

USA

design with control

group.
Policicchio et al (2011),

A quasi-experimental

Formal classroom component developed by researchers in groups, a DVD of FAS newborn followed by formal didactic education based on the guideline with Power point software and evaluation of newborn with the Finnegan Neonatal Abstinence Scoring Tool (FNAST) and with the help of the experts. Duration not mentioned.

Nurse Asthma Care Education (NACE) program modified by a university's centre. Program based on the national guidelines, which focused on the importance of providing treatment consistent with national guidelines, building effective relationships with patients and delivering key messages pertinent to asthma self-management for patients (10 specific techniques and 10 educational messages). A 5-hour seminar, slide presentations, video demonstration, role-play activities, case studies.

Educational certified intervention INROADS developed by university staff Into Pain Management, Optimal Analgesics and Drug Safety including latest findings on the pathophysiological pathways of pain as well as practical and evidence based approaches to the evaluation and management of patient pain, review of pharmacology and therapeutic rationale for major classes of pain medications and multimodal therapy with patient case examples, 10 meetings (workshops) and one satellite symposium.

Educational intervention developed by

Ang \& Chow (2010),

Singapore

A pre- and post-audit strategy.

university staff and based on best available

evidence for pain assessment,

documentation and analgesia administration reliability testing one week after

the educational offering

Mainly clinic/ambulatory care
facility or physician's office

caring for both children and

adults

34 nurses, post $=$ not mentioned

Hospital and pain clinics

93 nurses of the 527 nurses who participated in the INROADS

program

93 nurses with characteristics

similar to those of the

participants was chosen for a

control group.

Oncology ward in a acute care

setting including results of initial audit (good
24 nurses and all patients in the

ward
NACE program to measure perceived

helpfulness and confidence in providing

asthma services according to NACE

program.

Postintervention survey was conducted at the conclusion of the teaching session. SPSS Version 15.0, nonparametric sign test, Mann-Whitney $U$ test.

posttest, while scores of 7 of the participants $(10 \%)$ increased by 10 $\%$ or less.

All 10 nurses achieved a score of 90 $\%$ or more agreement according to the criteria when using the FNAST, four nurses scored $100 \%$ agreement

Significant changes in nurses' perceptions of the helpfulness of the National Asthma Education and Prevention Program Asthma Guidelines and their confidence to use the guidelines.

Survey with case vignettes was designed for this study and survey of barriers for analgesia, 30 days after the intervention

SPSS Version 18.0, descriptive statistics, $t$ test, Cohen's $d$ formula

GRIP program to identify gaps and barriers related to pain assessment and documentation, audit data: medical records of 24 patients, repeated 3 months after the implementation of practice change
The nurses participating into the INROADS program made their care choices statistically significantly more often based on the guidelines than the control group. Significantly greater number of them than nonparticipants reported that they felt "extremely confident" in their ability to provide optimal pain management to patients. Both groups indicated that the greatest barrier is a lack of adequate education dealing with pain management, followed by fear of contributing to a patient's addiction and lack of familiarity with evidencebased practices.

Compliance increased statistically significantly for all the three criteria: Increase in use of a pain assessment tool for patients with cancer, increase in the number of registered nurses 


\begin{tabular}{|c|c|c|c|c|}
\hline & $\begin{array}{l}\text { practices and developmental areas), } \\
\text { guidance for education to patients and their } \\
\text { caregivers and introduction to a formalized } \\
\text { pain and pain management assessment tool. } \\
\text { Workshop consisting three sessions ( } 5-6 \\
\text { persons in each), a replacement of a pain } \\
\text { management policy into a flow chart to be } \\
\text { inserted into patient's medical records and } \\
\text { briefing given, audit with feedback. }\end{array}$ & & $\begin{array}{l}\text { JBI-Paces program, descriptive statistics, } \\
\text { Fisher's exact test }\end{array}$ & $\begin{array}{l}\text { who received education in pain } \\
\text { assessment and increase for accuracy } \\
\text { in the assessment and documentation } \\
\text { of pain. }\end{array}$ \\
\hline $\begin{array}{l}\text { Anson } \text { et al }(2010), \text { USA } \\
\text { A single-group } \\
\text { pretest/posttest design. }\end{array}$ & $\begin{array}{l}\text { The educational program developed by } \\
\text { researchers (a } 38 \text {-minute, web-based tutorial } \\
\text { session) presented evidence-based } \\
\text { guidelines for venipuncture practices in } \\
\text { children: introduction of the importance of } \\
\text { the project by a nurse administrator, a short } \\
\text { video highlighting concerns raised by the } \\
\text { family advisory board, "worst-case" and } \\
\text { "best-case" scenario, proper assessment } \\
\text { techniques, communication, comfort } \\
\text { measures, site elections, insertion } \\
\text { techniques, securement, documentation, } \\
\text { complications, and staff resources. }\end{array}$ & $\begin{array}{l}\text { Medical-surgical units and } \\
\text { clinics at a pediatric Magnet } \\
\text { hospital } \\
939 \text { nurses in pre-test and } 603 \text { in } \\
\text { post-test ( } 4 \text { months after initial } \\
\text { data collection) }\end{array}$ & $\begin{array}{l}\text { Survey with also open ended questions } \\
\text { specifically developed for the current } \\
\text { project, } 426 \text { matched pre- and } \\
\text { posteducation surveys } \\
\text { SPSS Version } 12.0 \text {, chi-square and } t \text {-test } \\
\text { analyses, open ended responses were listed } \\
\text { and frequencies were reported. }\end{array}$ & $\begin{array}{l}\text { Statistically significant } \\
\text { improvements in the ability to grade } \\
\text { IV infiltrates, and phlebitis, a greater } \\
\text { willingness to allow parents to be } \\
\text { present during venipuncture (not } \\
\text { statistically significant) and to use } \\
\text { topical anesthetic agents before IV } \\
\text { placements and the need to limit } \\
\text { venipuncture to two attempts before } \\
\text { seeking additional support } \\
\text { (statistically significant). }\end{array}$ \\
\hline $\begin{array}{l}\text { Gance-Cleveland } \text { et al } \\
\text { (2009), USA } \\
\text { A quasi-experimental, } \\
\text { one-group, } \\
\text { pretest/posttest design. }\end{array}$ & $\begin{array}{l}\text { The 4-hour session developed by the } \\
\text { workgroup that had formulated the } \\
\text { guideline: an overview of the development } \\
\text { of the Healthy Eating and Activity Together } \\
\text { (HEAT) Guidelines, a summary of the } \\
\text { specific recommendations of it, introduction } \\
\text { to the role of the nurse practitioners, tools } \\
\text { available in the HEAT Resource Kit } \\
\text { (documentation guide, parent/patient } \\
\text { handouts, and rapid cycle improvement } \\
\text { worksheets), a training and demonstration on } \\
\text { motivational interviewing and counseling } \\
\text { technique. Case studies to role play. }\end{array}$ & $\begin{array}{l}\text { NAPNAP Annual conference } \\
\text { participants } \\
35 \text { nurse practitioners, mainly } \\
\text { from pediatrics } \\
32 \text { completed both the pre-test } \\
\text { and post-test evaluation at the } \\
\text { conclusion of the training. }\end{array}$ & $\begin{array}{l}\text { Questionnaire originally developed by } \\
\text { Expert Panel on Obesity Prevention in } \\
\text { Children and the International Life } \\
\text { Sciences Institute was adapted for this } \\
\text { study (17 questions), } \\
\text { SAS Version 9.1, descriptive statistics, } t \text { - } \\
\text { and v2 tests, }\end{array}$ & $\begin{array}{l}\text { Improvements in addressing the } \\
\text { barriers to the prevention of } \\
\text { overweight in youth, as well as } \\
\text { increased intent to change a practice. } \\
\text { Statistically significant } \\
\text { improvements in intent to conduct } \\
\text { growth assessment, assessment of } \\
\text { family history, and physical activity, } \\
\text { in knowledge regarding the } \\
\text { appropriate components of the family } \\
\text { health history related to risk for } \\
\text { overweight and in confidence to } \\
\text { modify behavior and engage the } \\
\text { whole family in the discussions and } \\
\text { age appropriate recommendations. }\end{array}$ \\
\hline
\end{tabular}


Table 4. Synthesis of the categories describing guideline implementation.

\begin{tabular}{|c|c|c|c|c|c|c|c|c|c|c|c|c|c|}
\hline $\begin{array}{l}\text { Categories describing guideline } \\
\text { implementation/publications }\end{array}$ & 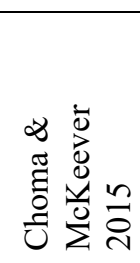 & 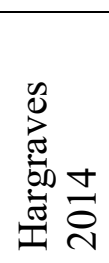 & 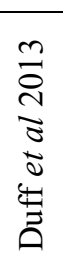 & 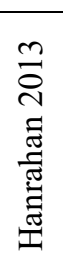 & 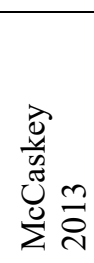 & 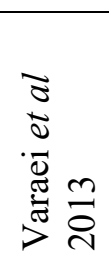 & 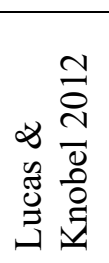 & 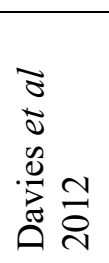 & 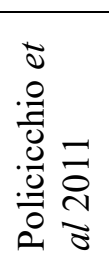 & 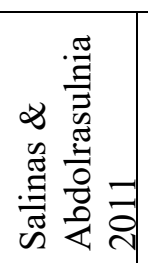 & 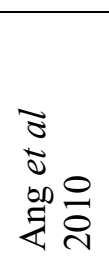 & 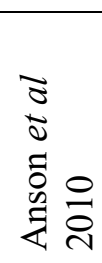 & 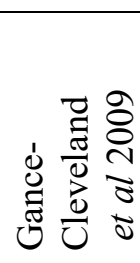 \\
\hline \multicolumn{14}{|l|}{$\begin{array}{l}\text { Contents of educational } \\
\text { interventions }\end{array}$} \\
\hline Basics of searching for evidence & & & & & & $\sqrt{ }$ & & & & & & & \\
\hline $\begin{array}{l}\text { Presentation of the guideline and } \\
\text { tools based on it }\end{array}$ & $\checkmark$ & $\checkmark$ & $\checkmark$ & $\checkmark$ & $\sqrt{ }$ & & $\sqrt{ }$ & $\sqrt{ }$ & $\checkmark$ & $\sqrt{ }$ & $\checkmark$ & $\sqrt{ }$ & $\sqrt{ }$ \\
\hline $\begin{array}{l}\text { Overview of the needs for changing } \\
\text { practice }\end{array}$ & & & $\checkmark$ & & $\sqrt{ }$ & & & & & $\sqrt{ }$ & $\checkmark$ & $\sqrt{ }$ & \\
\hline $\begin{array}{l}\text { Delivery of the information } \\
\text { included in the guideline to patients } \\
\text { and families }\end{array}$ & & & & & & & & $\sqrt{ }$ & $\checkmark$ & & $\checkmark$ & $\sqrt{ }$ & $\sqrt{ }$ \\
\hline $\begin{array}{l}\text { Education and counselling of } \\
\text { patients and families }\end{array}$ & & & & & & & & $\checkmark$ & $\checkmark$ & & $\checkmark$ & & $\checkmark$ \\
\hline \multicolumn{14}{|l|}{$\begin{array}{l}\text { Teaching/learning methods of } \\
\text { educational interventions }\end{array}$} \\
\hline Face-to-face lectures & & $\checkmark$ & $\checkmark$ & $\checkmark$ & & & $\sqrt{ }$ & $\sqrt{ }$ & $\checkmark$ & & & $\checkmark$ & $\sqrt{ }$ \\
\hline Web-based sessions & $\checkmark$ & & & & $\sqrt{ }$ & & & & & & & & \\
\hline Small group work & & & & & $\sqrt{ }$ & $\checkmark$ & $\sqrt{ }$ & & $\checkmark$ & $\checkmark$ & $\checkmark$ & & \\
\hline Audiovisual methods & & & $\sqrt{ }$ & $\checkmark$ & & & $\checkmark$ & & $\checkmark$ & & & $\checkmark$ & \\
\hline $\begin{array}{l}\text { Case examples and role-play } \\
\text { activities }\end{array}$ & & & & & & & & & $\checkmark$ & $\checkmark$ & & & $\sqrt{ }$ \\
\hline Demonstrations/Practical exercises & & $\checkmark$ & $\sqrt{ }$ & & $\checkmark$ & & $\checkmark$ & & & & & & \\
\hline $\begin{array}{l}\text { Simultaneous strategies for } \\
\text { implementation }\end{array}$ & & & & & & & & & & & & & \\
\hline
\end{tabular}




\begin{tabular}{|c|c|c|c|c|c|c|c|c|c|c|c|c|c|}
\hline $\begin{array}{l}\text { Revisions of local procedures and } \\
\text { protocols }\end{array}$ & & $\checkmark$ & & $\sqrt{ }$ & & $\sqrt{ }$ & & $\checkmark$ & & & $\checkmark$ & & \\
\hline Facilitation with feedback & & $\sqrt{ }$ & $\checkmark$ & & & & & $\checkmark$ & & & $\checkmark$ & & \\
\hline Audit with feedback & & & $\checkmark$ & $\checkmark$ & $\checkmark$ & $\checkmark$ & & & & & $\checkmark$ & & \\
\hline Support for decision-making & & & & $\checkmark$ & & & & & & & & & \\
\hline Multiprofessional collaboration & & $\checkmark$ & $\checkmark$ & $\checkmark$ & & & & $\checkmark$ & & & & & \\
\hline \multicolumn{14}{|l|}{$\begin{array}{l}\text { Outcomes of the educational } \\
\text { interventions and strategies }\end{array}$} \\
\hline $\begin{array}{l}\text { Positive changes in nurses' } \\
\text { attitudes }\end{array}$ & & & & & & $\mathbf{X}$ & & $\mathbf{X}$ & $\mathbf{X}$ & & $\mathbf{X}$ & & $\mathbf{X}$ \\
\hline $\begin{array}{l}\text { Improvement in nurses' knowledge } \\
\text { base }\end{array}$ & $\mathbf{X}$ & $\mathbf{X}$ & & $\mathrm{x}$ & & $\mathbf{X}$ & $\mathbf{X}$ & $\mathbf{X}$ & & & & & $\mathbf{X}$ \\
\hline $\begin{array}{l}\text { Nurses' enhanced confidence in } \\
\text { using guidelines and changing } \\
\text { practices }\end{array}$ & & & & & & & & & $\mathbf{X}$ & $\mathbf{X}$ & & & $\mathbf{X}$ \\
\hline $\begin{array}{l}\text { Self-reported improvement in } \\
\text { nurses' evidence-based decision } \\
\text { making and care practices based on } \\
\text { guidelines }\end{array}$ & $\mathrm{x}$ & & & $\mathrm{x}$ & $\mathbf{X}$ & $\mathbf{X}$ & & $\mathbf{X}$ & & $\mathbf{X}$ & $\mathbf{X}$ & $\mathbf{X}$ & $\mathbf{X}$ \\
\hline Improvements in the quality of care & & $\mathbf{X}$ & & $\mathbf{X}$ & $\mathrm{x}$ & & & $\mathrm{x}$ & & & $\mathbf{X}$ & $\mathrm{x}$ & \\
\hline
\end{tabular}

Included in the intervention $(\checkmark)$, statistically significant improvements $(\mathbf{X})$, improvements, but no statistically significant (x) 